\title{
Chatbot Untuk Customer Service Berbasis Teks dan Suara pada Sistem Manajemen Pemesanan (OMS) Menggunakan Platform Android
}

\author{
Adi Nugroho ${ }^{* 1}$, Derry Pramono Adi $^{2}$, Agustinus Bimo Gumelar ${ }^{3}$ \\ ${ }_{1,2,3}$ Fakultas Ilmu Komputer/Universitas Narotama \\ adi.nugroho@fik.narotama.ac.id ${ }^{* 1}$, derryalbertus@ieee.org ${ }^{2}$, bimogumelar@ieee.org ${ }^{3}$
}

\begin{abstract}
Abstrak
Kualitas penyediaan saluran layanan pelanggan sangat berpengaruh terhadap tingkat kepuasan pelanggan dalam suatu transaksi jual beli. Dengan pelayanan yang baik akan mewujudkan hubungan yang harmonis antara perusahaan dengan pelanggan. Untuk mendapatkan kepuasan pelanggan maka diperlukan adanya interaksi yang baik dari seorang customer service kepada pelanggan, mulai dari pelanggan melakukan pemesanan sampai pelanggan selesai melakukan pembelian. Makalah ini mengusulkan pengembangan chatbot yang berperan sebagai customer service yang dapat berkomunikasi dan melayani pelanggan dalam melakukan pemesanan. Pelanggan dapat berkomunikasi dengan chatbot untuk mengetahui tentang informasi dari produk yang akan dipesan. Pelanggan dapat melakukan interaksi percakapan dalam bentuk teks dan suara. Setelah pelanggan selesai melakukan pemesanan, chatbot akan memberikan notifikasi kepada bagian produksi untuk melakukan konfirmasi ketersedian produk yang dipesan oleh pelanggan. Bagian produksi akan melakukan konfirmasi ketersediaan produk didalam sistem manajemen pemesanan (OMS). Chatbot akan mengrimkan detail pemesanan kedalam OMS sehingga bagian produksi bisa langsung melakukan pemrosesan pesanan dari pelanggan. Chatbot akan dibangun didalam platform android dan menggunakan platform NLP (Natural Language Processing) yaitu Dialogflow. Platform ini yang nantinya akan memproses dan melakukan pemindaian terhadap setiap pertanyaan yang diberikan oleh pelanggan. Didalam platform Dialogflow, penulis akan membuat intent dan juga response untuk melakukan penanganan percakapan yang diberikan oleh pelanggan mengenai proses pemesanan.
\end{abstract}

Kata Kunci: Chatbot, Customer Service, Sistem Manajemen pemesanan, Dialogflow, Android

\begin{abstract}
The quality of providing customer service channels is very influential on the level of customer satisfaction in a sale and purchase transaction. Good service will create a harmonious relationship between the company and customers. To get customer satisfaction, it requires a good interaction from customer service to the customer, starting from the customer making an order until the customer has finished making a purchase. This paper proposes the development of chatbot which acts as a customer service that can communicate and serve customers in placing an order. Customers can communicate with the chatbot to find out about information from the product to be ordered. Customers can make conversation interactions in the form of text and voice. After the customer has finished making an order, a chatbot will give a notification to the production department to confirm the availability of the ordered product. The production department will confirm product availability in the order management system (OMS). Chatbot will send order details into CSO so that the production department can directly process orders from customers. Chatbot will be built on the Android platform and use the NLP (Natural Language Processing) platform, namely Dialogflow. This platform will later process and scan every question given by the customer. In the Dialogflow platform, the writer will make an intent and also a response to handle the conversation given by the customer regarding the ordering process.
\end{abstract}

Keywords: Chatbot, Customer Service, Order Management System, Dialogflow, Android

\section{Pendahuluan}

Saluran layanan pelanggan merupakan jembatan bagi perusahaan dalam berkomunikasi dengan pelanggannya. Dengan memberikan kualitas pelayanan yang baik dalam saluran layanan 
pelanggan, tentunya akan memberikan kepuasan untuk pelanggan dan meningkatkan hubungan antara peruahaan dengan pelanggan [1]. Untuk mendapatkan kepuasan dari pelanggan dibutuhkan pelayanan yang bisa memberikan tanggapan secara real-time. Penyediaan saluran layanan pelanggan dengan suatu pesan instan dapat meringankan beban operasional jika ditinjau dari segi aspek sumber daya manusia dengan cara memberikan layanan untuk menjawab pertanyaan yang normatif dan mengulang [2]. Pertanyaan yang bersifat mengulang dengan struktur bahasa yang tidak baku sering dijadikan fitur dalam sebuah saluran layanan pelanggan [3][4] Dengan keterbatasan kemampuan manusia dalam hal menangani pelanggan dalam satu waktu menjadikan kelemahan dalam sebuah saluran layanan pelanggan. Oleh karena itu diperlukan sistem chatbot sebagai salah satu solusi dalam sebuah saluran layanan pelanggan agar mempermudah komunikasi antara perusahaan dan pelanggan secara virtual [5]

Perkembangan teknologi informasi berbasis komputer yang semakin pesat telah membuat banyak perubahan dalam berbagai bidang kehidupan manusia. Salah satu perkembangan teknologi saat ini adalah kecerdasan buatan, manusia mampu membuat mesin atau robot yang memiliki kecerdasan menyerupai manusia yang dibuat menggunakan sebuah bahasa yang membentuk abstraksi dan konsep [6]. Dengan menggunakan kecerdasan buatan maka tidaklah mustahil akan ada mesin yang benar-benar mampu berpikir, bertindak, mendengar, melihat, dan berbicara layaknya manusia [7]. Contoh mesin yang dapat berkomunikasi adalah chatbot [8]. Dengan sistem kerja yang dimiliki oleh chatbot, nantinya pelanggan dapat dengan mudah mencari sebuah informasi yang diinginkan [9]. Keberadaan chatbot sebagai layanan digital berbasis kecerdasan buatan yang mempunyai kemampuan percakapan dianggap efektif untuk memberikan pelayanan kepada pelanggan. Chatbot bisa mengambil alih komunikasi yang berulang-ulang dan mengurangi beban operasional yang sebelumnya dikerjakan oleh manusia [10]

Dalam makalah ini menjelaskan dan mengusulkan pengembangan chatbot yang berperan sebagai customer service yang dapat berkomunikasi dan melayani pelanggan dalam hal pemesanan. Chatbot akan memberikan informasi kepada para pelanggan yang ingin sekedar bertanya mengenai produk atau pelanggan yang ingin menanyakan progress dari produk yang sudah dipesan. Pelanggan bisa berinteraksi dengan chatbot melalui tampilan obrolan antarmuka, interaksi tersebut berbentuk teks dan suara yang akan memberikan kesan seakan pelanggan melakukan komunikasi langsung dengan customer service. Chatbot dibangun menggunakan platform android agar setiap pelanggan yang memiliki smartphone bisa mengakses chatbot tersebut. Dalam penelitian ini pembangunan chatbot menggunakan framework Dialogflow dengan fokus pemanfaatan chatbot pada sistem pengelola data pesanan dari pelanggan yang disebut Order Management System (OMS).

Makalah ini disusun sebagai berikut. Bagian I menguraikan motivasi dari penelitian. Bagian II membahas tentang ulasan literatur terkait dengan topik penelitian ini. Bagian III membahas tentang pembangunan model dari penelitian. Bagian IV membahas tentang hasil dari model penelitian. Bagian $\mathrm{V}$ menyajikan ringkasan temuan dari penelitian dan kontribusi untuk penelitian di masa mendatang.

\section{Kajian Pustaka}

Teknologi chatbot telah mengalami perkembangan yang sangat pesat dan telah merambah ke dalam dunia bisnis. diperkirakan beberapa tahun kemudian interaksi pelanggan tidak akan ditangani lagi oleh manusia. Chatbot tidak hanya mampu memberikan tanggapan terhadap pertanyaan pelanggan, melainkan juga untuk tugas bisnis lainnya seperti mengumpulkan informasi tentang pengguna, mengatur jadwal pertemuan dll. Di sisi lain chatbot juga dapat menghemat biaya oerasional yang sebelumnya dikerjakan oleh manusia [5].

Di dalam penelitian terdahulu [11], dijelaskan penggunaan chatbot pada usaha mikro kecil menengah yang diimplementasikan ke dalam sistem manajemen pemesanan. Chatbot berperan sebagai media unruk pelanggan agar dapat berkomunikasi dengan usaha tersebut secara otomatis. Chatbot dikembangkan di dalam platform perpesanan yaitu Messenger dan menggunakan platform NLP (Natural Language Processing) yaitu API.Al agar chatbot dapat memahami pertanyaan yang diajukan oleh pelanggan. Chatbot dirancang untuk manangani percakapan kepada pelanggan dalam melakukan pemesanan dan pemeriksaan pesanan.

Ada banyak jenis platform yang bisa digunakan untuk mengembangkan chatbot seperti Dialogflow pada Google, wit.ai milik Facebook, Watson milik IBM, LUIS milik Microsoft, Lex Amazon dll. Di Indonesia sendiri, teknologi chatbot sudah mulai berkembang; terdapat dua

REPOSITOR, Vol. 2, No. 6, Juni 2020: 683-690 
platform untuk mengembangkan chatbot yaitu Kata.ai dan Bahasa.ai. Masing-masing platform tersebut tentunya memiliki kemampuan yang berbeda dalam menangani pemrosesan bahasa alami.

\subsection{Dialogflow Framework}

Dialogflow, yang sebelumnya dikenal dengan nama api.ai, merupakan platform pemrosesan percakapan yang dimiliki dan dikelola oleh Google [12]. Platform ini mendukung berbagai macam bahasa diantaranya bahasa Indonesia, serta dapat diintegrasikan dengan platform perpesanan seperti Telegram, Messenger dan juga bisa diintegrasikan dengan virtual asisten seperti Google Asisten, Amazon Alexa dll.

Dialogflow menyediakan fitur-fitur yang memungkinkan untuk mengolah percakapan dengan pengguna, diantaranya:

1. Agent: sebagai manajemen flow percakapan.

2. Intents: manajer dialog untuk mendesain pertanyaan dan jawaban yang akan digunakan sebagai percakapan dengan pelanggan, contoh intents: salam, daftar menu, nama, dll.

3. Entities: mengidentifikasi pertanyaan dari user, apakah memiliki kesamaan dengan katakunci pada entities atau tidak. Contoh entities : @makanan, @minuman, dll.

4. Menghasilkan bentuk JSON untuk mengenali pertanyaan pengguna dari intents dan entities. Serta untuk mengirimkan data kedalam OMS.

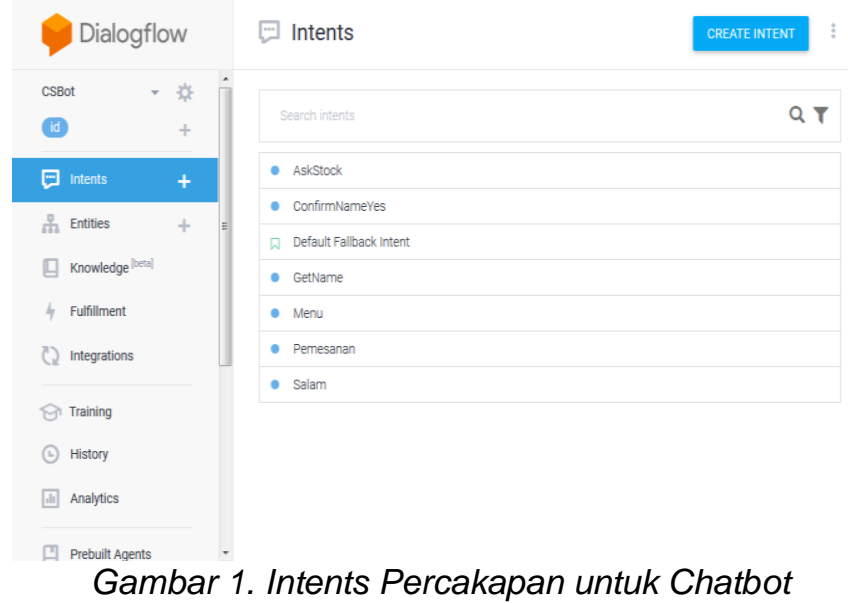

Gambar 1 merupakan sebagian tampilan Intents yang telah dibuat untuk menangani pertanyaan dari user. Pertanyaan dari pelanggan akan diperiksa dan dicocokan dengan isi dari Intents yang telah dibuat. Jika pertanyaan tidak ada yang cocok dengan Intents, maka chatbot akan menggunakan fitur "Default Fallback Intents" untuk menangani pertanyaan dari pelanggan yang tidak cocok dengan maksud yang telah ditentukan sebelumnya.

\subsection{Order Management System (OMS)}

Order Management System (OMS) adalah sistem yang dapat membantu mengelola data pesanan dari pelanggan yang melakukan transaksi pembelian produk dari pemilik usaha tersebut. Pada umumnya, Order Management System digunakan untuk melakukan proses pencatatan pesanan ke dalam sebuah basis data agar mempermudah pelaku usaha untuk melakukan pengecekan ataupun membuat sebuah laporan tentang transaksi penjualan yang telah dilakukan [3].

Gambar 2 merupakan tampilan halaman utama pada OMS yang akan diintegrasikan dengan chatbot. Di dalam OMS tersebut terdapat beberapa modul-modul yang digunakan untuk mendukung sistem di antaranya:

1. Food Menu: untuk mengelola produk seperti menambah produk dan mengubah harga produk.

2. Orders: untuk mengelola pesanan dari pelanggan (pesanan yang telah selesai ataupun pesanan yang dibatalkan).

3. User: untuk mengelola informasi tentang data pelanggan.

Pelanggan akan melakukan pemesanan produk melalui aplikasi chatbot, kemudian chatbot akan mengirimkan notifikasi kepada bagian produksi untuk melakukan konfirmasi ketersedian 
produk melalui OMS. Setelah pelanggan selesai melakukan pemesanan, chatbot akan mengirimkan detai pesanan dari pelanggan kedalam OMS agar pesanan dapat segera diproses.

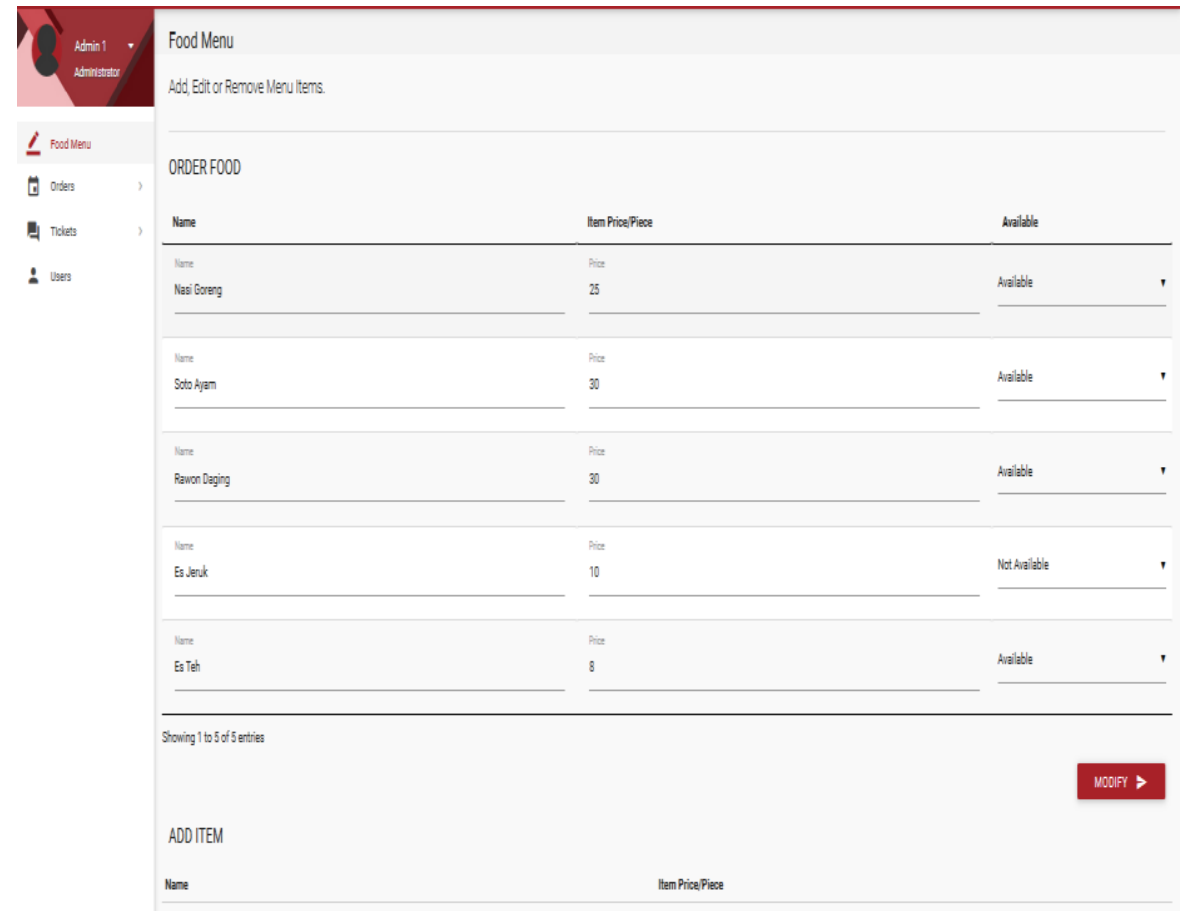

Gambar 2. Order Management System: Halaman Food Menu

\section{Metode Penelitian}

Chatbot yang akan dikembangkan berbasis teks dan juga suara, sehingga pelanggan bisa melakukan interaksi percakapan menggunakan inputan teks dan juga suara. Chatbot dibangun didalam platform android. Chatbot akan mengambil informasi tentang produk dari basis data yang digunakan untuk OMS.

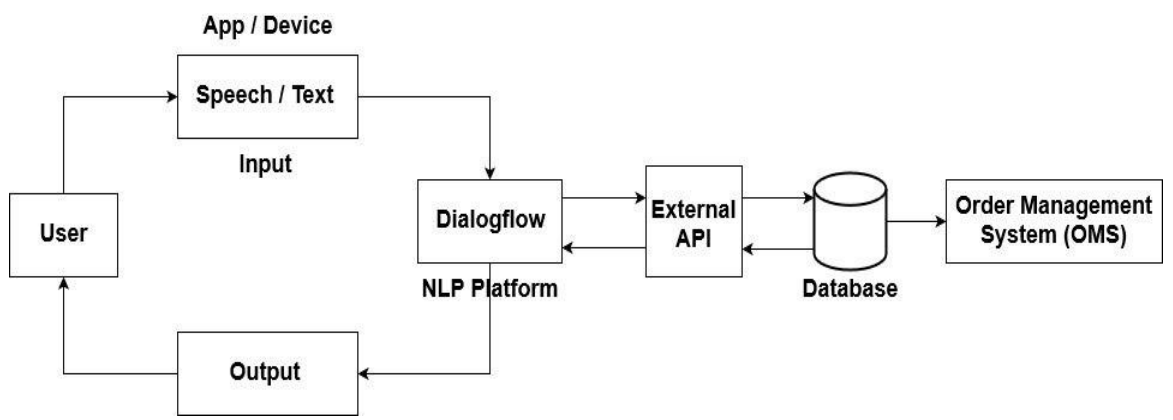

Gambar 3. Alur Kerja Sistem Chatbot

Gambar 3 menjelaskan alur kerja dari system chatbot dalam menangani pertanyaan dari pelanggan. Alur kerja dimulai dari pelanggan menginputkan pertanyaan kepada chatbot dalam bentuk teks maupun suara, misalnya pelanggan bertanya tentang harga sebuah produk atau pelanggan ingin melakukan pemesanan produk. Kemudian chatbot akan mengirimkan pertanyaan tersebut kedalam Dialogflow, platform ini yang akan mencocokan inputan pertanyaan dari user dengan intents yang telah dibuat yang ada pada Gambar 2. Selain melakukan pencocokan dengan intents dan juga entities yang telah dibuat, Dialogflow akan mengambil data dari basis data yang telah dibuat untuk OMS untuk mendapatkan informasi tentang produk. Chatbot akan mengirimkan detail pesanan dari pelanggan kedalam OMS agar pesanan bisa segera diproses. Selanjutnya chatbot akan membalas pertanyaan dari pelanggan dalam bentuk teks.

REPOSITOR, Vol. 2, No. 6, Juni 2020: 683-690 


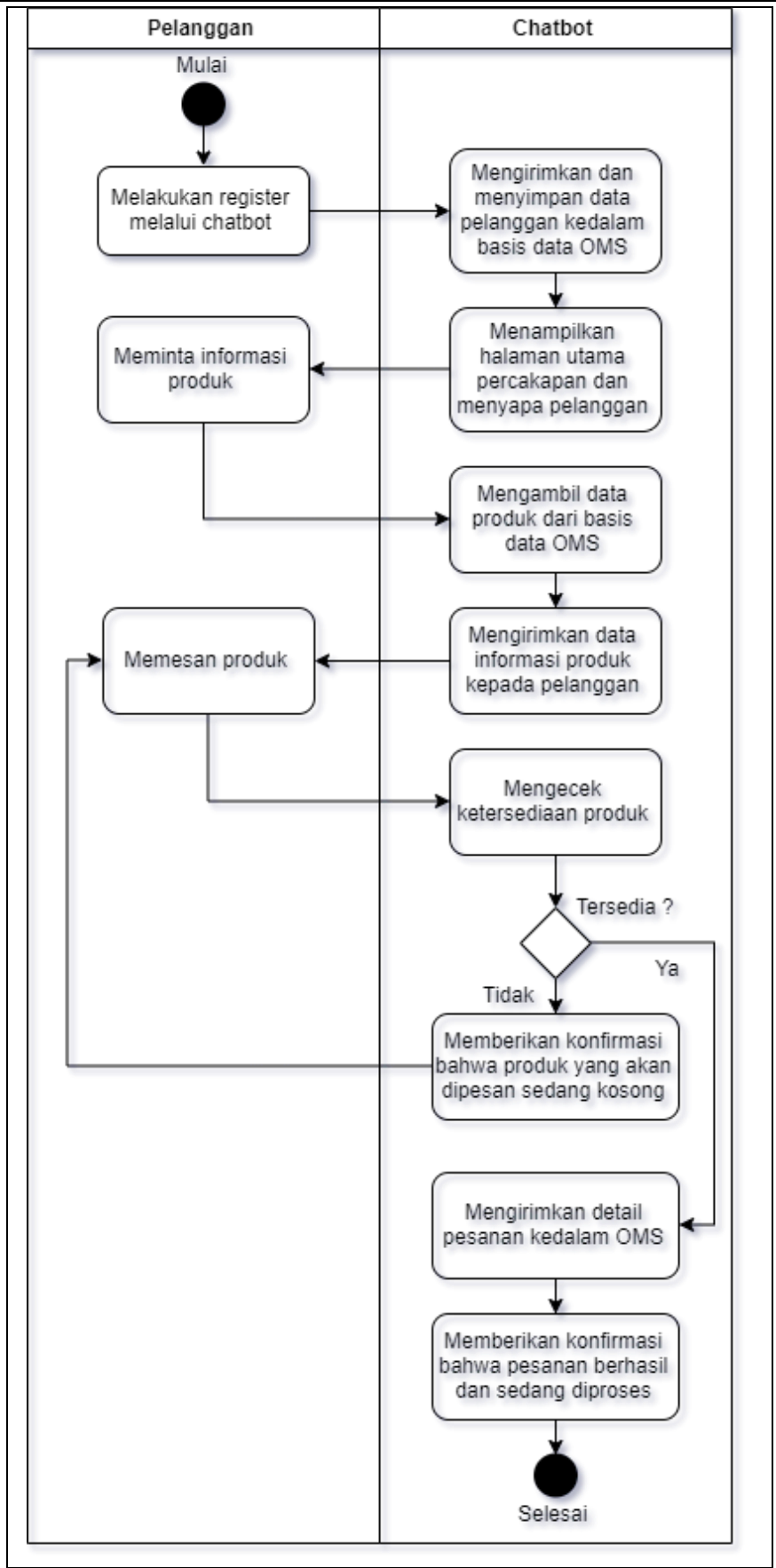

Gambar 4. Alur Pemesanan Produk Pada Chatbot

Gambar 4 menjelaskan tentang proses pemesanan produk yang dilakukan oleh pelanggan. Dimulai dari pelanggan melakukan register melalui chatbot, kemudian chatbot mengirimkan dan menyimpan data pelanggan kedalam basis data OMS. Setelah berhasil registrasi, pelanggan akan masuk kedalam halaman utama yaitu halaman percakapan. Di halaman ini pelanggan bisa mengajukan pertanyaan tentang informasi produk dan juga melakukan pemesanan. Setelah pelanggan mendapatkan informasi dari produk yang akan dipesan, selanjutnya pelanggan akan melakukan pemesanan. Chatbot akan mengirimkan notifikasi kepada bagian produksi melalui OMS agar melakukan konfirmasi ketersediaan produk. Jika produk tersedia, maka chatbot akan meberikan informasi kepada pelanggan bahwa produk tersedia dan memastikan kembali pesanan tersebut. Jika produk tidak tersedia, maka chatbot akan meberikan konfirmasi kepada pelanggan bahwa produk yang akan dipesan sedang kosong. Setelah pelanggan melakukan pemesanan, chatbot akan mengirimkan data detail pesanan 
produk dari pelanggan kedalam OMS agar pesanan dapat segera diproses. Kemudian chatbot akan memberikan konfirmasi kepada pelanggan bahwa pemesanan produk telah berhasil dan pesanan sedang diproses.

\section{Hasil Penelitian dan Pembahasan}

Chatbot akan diintegrasikan dengan Order Management System (OMS) yang akan berperan sebagai customer service yang akan melayani pelanggan dalam hal pemesanan produk. Mulai dari pelanggan yang ingin bertanya tentang informasi sebuah produk, pelanggan yang ingin memesan produk dan pelanggan yang ingin mengetahui sejauh mana proses pesanan produk yang telah mereka pesan, seperti yang ditunjukkan pada Gambar 5, Gambar 6, Gambar 7, dan Gambar 8.

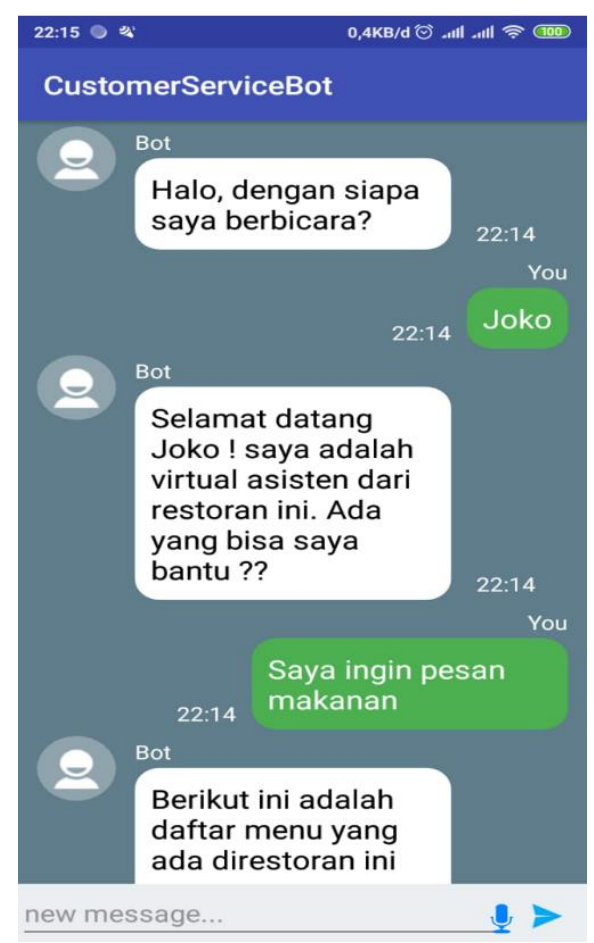

Gambar 5. Tampilan Chatbot di Android

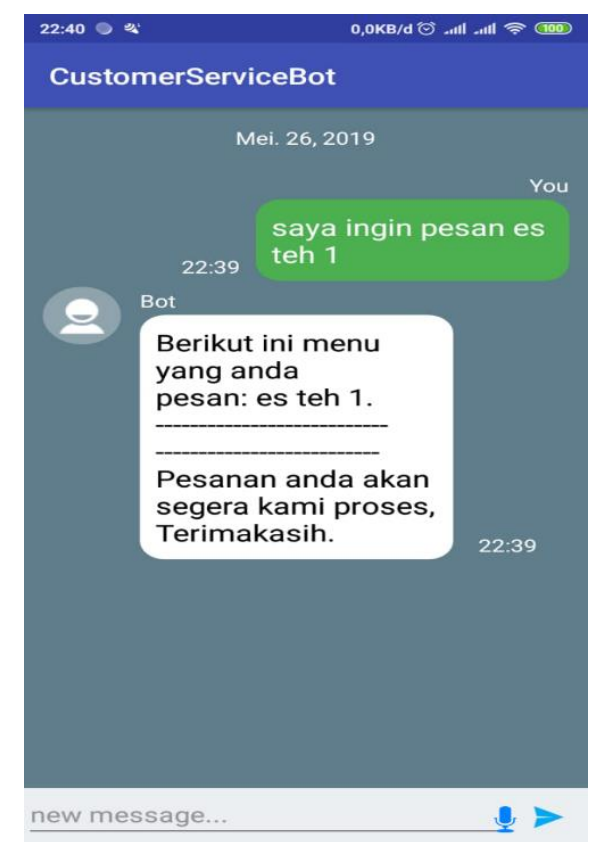

Gambar 6. Tampilan Chatbot di Android (lanj.)

REPOSITOR, Vol. 2, No. 6, Juni 2020: 683-690 


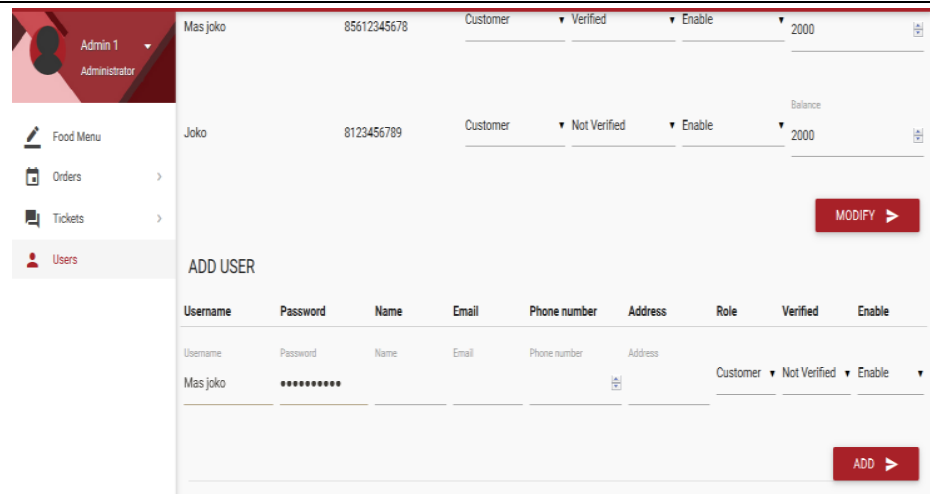

Gambar 7. Data User di OMS Setelah Register Melalui Chatbot

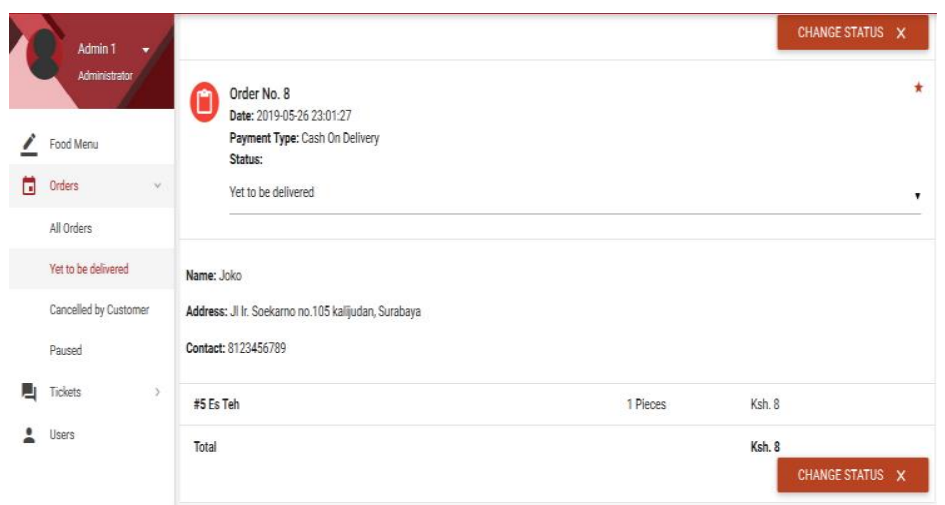

Gambar 8. Data Pesanan Pelanggan yang Dikirim Oleh Chatbot ke Dalam OMS

\section{Kesimpulan}

Makalah ini membahas tentang usulan pembangunan chatbot berbasis suara dan teks yang diintegrasikan kedalam sebuah OMS. Chatbot dikembangkan menggunakan framework Dialogflow. Chatbot dibatasi dalam pelayanan pemesanan produk, tidak sampai melayani pelanggan dalam melakukan pembayaran. Respon dari chatbot juga masih dalam bentuk teks. Untuk pengembangan lebih lanjut, kami akan melengkapi chatbot dengan kemampuan untuk membalas pertanyaan pelanggan menggunakan respon suara jika pelanggan melakukan interaksi percakapan menggunakan suara.

\section{Referensi}

[1] A. Caruana, "Service Loyalty: The Effects of Service Quality and the Mediating Role of Customer Satisfaction," Eur. J. Mark., vol. 36, no. 7/8, pp. 811-828, Aug. 2002, doi: $10.1108 / 03090560210430818$.

[2] T. M. Nisar, Smartphone and App Implementations that Improve Productivity. Berlin, Boston: De Gruyter, 2019.

[3] J. A. Goodman, Strategic Customer Service: Managing the Customer Experience to Increase Positive Word of Mouth, Build Loyalty, and Maximize Profits, 1st ed. AMACOM, 2009.

[4] M. Ates, "Artificial intelligence in banking: A Case Study of the Introduction of a Virtual Assistant into Customer Service," Jönköping University, Jönköping International Business School, 2017.

[5] B. Abu Shawar and E. Atwell, "Chatbots: are they really useful?," LDV-Forum Zeitschrift für Comput. und Sprachtechnologie, vol. 22, no. 1, pp. 29-49, 2007.

[6] D. P. Adi, A. B. Gumelar, and R. P. Arta Meisa, "Interlanguage of Automatic Speech Recognition," in 2019 International Seminar on Application for Technology of Information and Communication (iSemantic), 2019, pp. 88-93, doi: 10.1109/ISEMANTIC.2019.8884310.

[7] A. B. Gumelar et al., "Human Voice Emotion Identification Using Prosodic and Spectral Feature Extraction Based on Deep Neural Networks," in 2019 IEEE 7th International Conference on Serious Games and Applications for Health (SeGAH), 2019, pp. 1-8. 
[8] S. Quarteroni and S. Manandhar, "A Chatbot-based Interactive Question Answering System," in Decalog 2007: Proceedings of the 11th Workshop on the Semantics and Pragmatics of Dialogue, 2007, pp. 83-90.

[9] F. Clarizia, F. Colace, M. Lombardi, F. Pascale, and D. Santaniello, "Chatbot: An Education Support System for Student," 2018, pp. 291-302.

[10] F. Examiner, S. Examiner, and J. Vogel, "Chatbots : Development and Applications," 2017.

[11] M. S. Satu, T. M. N. U. Akhund, and M. A. Yousuf, "Online Shopping Management System with Customer Multi-Language Supported Query handling AIML Chatbot," 2017, doi: 10.13140/RG.2.2.10508.10885.

[12] M. Canonico and L. De Russis, "A Comparison and Critique of Natural Language Understanding Tools," CLOUD Comput. 2018 Ninth Int. Conf. Cloud Comput. GRIDs, Virtualization, no. c, pp. 110-115, 2018. 